\title{
SEMICARBAZONES AS ANTICONVULSANTS
}

\section{BY}

Mohamed Nabil Aboul-Enein ${ }^{1 *}$, Aida Abd El-Sattar El-Azzouny ${ }^{1}$, Kamilia M. Amin ${ }^{2}$, Youssreya A. Maklad ${ }^{1}$, Mohamed Ibrahim Attia ${ }^{1}$, and Mohammed Farrag El-Behairy .

\section{From}

${ }^{1}$ Medicinal and Pharmaceutical Chemistry Department, Pharmaceutical and Drug Industries Research Division, National Research Centre, Dokki, Giza,12622, Egypt

${ }^{2}$ Department of pharmaceutical Chemistry, Faculty of Pharmacy, Cairo University, Cairo, Egypt

\begin{abstract}
Approximately $25 \%$ of epileptics' convulsions are inefficiently controlled by currently available remedies; therefore the preparation of new antiepileptic drugs is of great interest. Aryl semicarbazones can be considered a new class of compounds presenting anticonvulsant activity. In addition, they can be orally administered. Semicarbazones derived from aromatic and unsaturated carbonyl compounds as well as from other precursors are reviewed together with their anticonvulsant profile.
\end{abstract}

Key words: Semicarbazone, Anticonvulsant, pentylenetetrazole (PTZ), maximal electroshock (MES).

\section{INTRODUCTION:}

Aryl semicarbazones have been documented to contribute in the design of novel anticonvulsant agents, due to their excellent activity in the maximal electroshock seizure (MES) in both mice and rats and also against clonic seizures induced by pentylenetetrazole (PTZ) in mice, being more active than some conventional AEDs, beside their low neurotoxicity (Rajak, et al., 2009). Semicarbazones have been developed due to their structural dissimilarity from many common monocyclic anticonvulsants containing the dicarboximide function (CONRCO) which may contribute to toxic side effects, so it can be assumed that such novel compounds would not have the side effects seen with many of the currently available anticonvulsant medications (Kadaba 1984).

A pharmacophoric model has been put forward for antiepileptic activity owing to conformational investigations on prevailing anticonvulsant drugs such as phenytoin, carbamazepine, lamotrigine and phenobarbitone (Pandeya, et al., 1999). This semicarbazones based pharmacophoric mode 1 comprises the following four essential binding sites (Dimmock, et al., 2000; Pandeya, et al., 2002):

(A) An aryl hydrophobic binding domain with substituent preferably at para position

(B) A hydrogen bonding site

(C) An electron donor moiety

(D) Another hydrophobic-hydrophilic domain (distal hydrophobic domain) regulating the pharmacokinetic properties of the anticonvulsant (Fig. 1). 


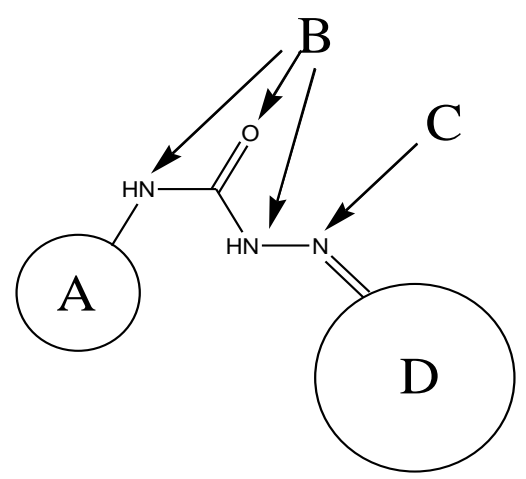

Fig. 1: Semicarbazone based pharmacophoric model and its vital structural features (Dimmock, et al., 2000; Pandeya 2002).

\section{Bioactive semicarbazones:}

In the last 25 years, in addition to the patented data (Dimmock 1994; Dimmock and Puthucode 1996; Wang et al., 1998; Kadaba et al., 1999; Schann 2008), a series of publications reporting on the anticonvulsant activity of semicarbazones derived from aromatic and unsaturated carbonyl compounds as well as from other precursors has been launched. The following survey comprises most of these publications.

A series of thiosemicarbazones and semicarbazones of arylidene methyl ketones have been prepared and evaluated in the maximal electroshock (MES) and subcutaneous pentylenetetrazole (scPTZ) screens. Compound 1 had an $\mathrm{ED}_{50}$ of $6.96 \mathrm{mg} / \mathrm{kg}$ in the scPTZ test when administered by intraperitoneal route (i.p.) to mice, and a protection index of 10.37 when given orally (Dimmock et al., 1986).

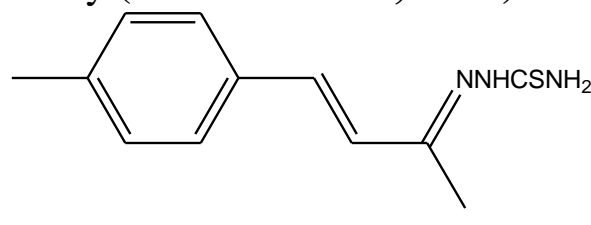

1

New study (Dimmock et al., 1993) with particular goal of finding compounds with oral activity has been designed with the exclusion of thiosemicarbazones due to its neurotoxicity and lethality (Dimmock et al., 1990; 1991). Most of the synthesized compounds displayed anticonvulsant activity in MES and scPTZ screens when given to mice by i.p. route. Compound 2 showed the best activity in both models (PI > 5.53 MES and $>2.82 \mathrm{scPTZ}$ ). Oral administration of the compounds to rats led to excellent potency in the MES screen while virtually no activity in the scPTZ test was displayed.

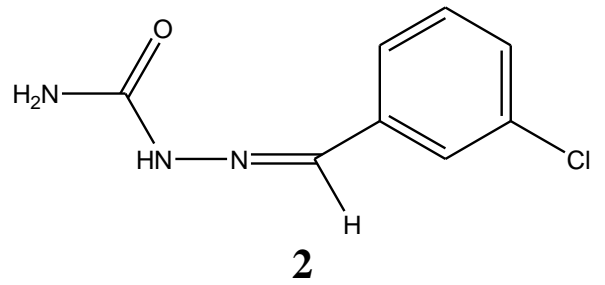

As a continuation of the former work, a molecular modeling study has been performed by Dimmock et al. (1995) to develop structure-activity relationship (SAR) of the previously synthesized series of anticonvulsants. Compound $\mathbf{3}$ was designated the lead compound based on detailed evaluation of its anticonvulsant properties (Dimmock and Baker 1994). The study revealed that the presence of a large hydrophobic group in 
close proximity to at least two electron-donor atoms is required for MES activity while, for scPTZ a smaller less hydrophobic group should be present near to a minimum of two electrondonor atoms.

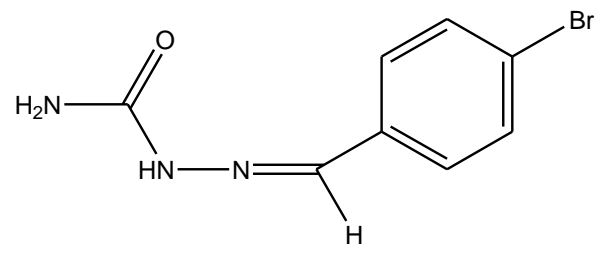

3

In order to examine the effect of structure restriction on the anticonvulsant activity, new semicarbazone derivatives of 1-indanone, 1-tetralone, 1-benzosuberone, 2indanone and 2-tetralone, as frozen analogues of the previously synthesized semicarbazones, have been synthesized and tested for its activity by Dimmock $\boldsymbol{e t}$ al. (1995). The potency of compound 4 was 2.98 times that of the acyclic analogue and greater activity than both phenytoin and valproate with a PI of approximately 40 .

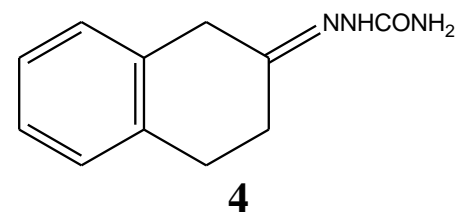

For more understanding of the putative binding site two studies have been performed by Dimmock et al. (1996) and (2000). The first study has been aimed at investigation of the role of the aryl moiety in anticonvulsant activity, thus a new series of 95 (aryloxy)aryl semicarbazones and related compounds has been synthesized, biologically evaluated and many quantitative structure-activity relationships (QSAR) and $\mathrm{X}$-ray crystallographic studies have been performed. Compound $\mathbf{5}$ was the most active candidate showing activity in both models at $30 \mathrm{mg} / \mathrm{kg}$.

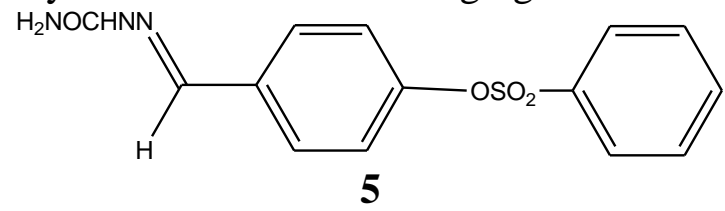

The second study has been particularly oriented towards the hydrogen bonding area. Several compounds have been synthesized following sequential changes in the terminal electron-rich group. It has been revealed that terminal electron-rich groups enhanced the hydrogen bonding capabilities and anticonvulsant properties.

As a part of Dimmocks' research group, Puthucode et al. (1998) have used Dimmocks' compounds $\mathbf{1}$ and $\mathbf{5}$ as prototypic molecules for subsequent molecular modification. The study has identified a number of highly promising anticonvulsant semicarbazones derived from aryl, arylidene and aryloxyaryl ketones and aldehydes. Attachment of a 2-naphthyloxy group (compound 6) gave high activity in the rat oral MES screen $\left(\mathrm{ED}_{50}=26.8, \mathrm{PI}=18.7\right)$. 


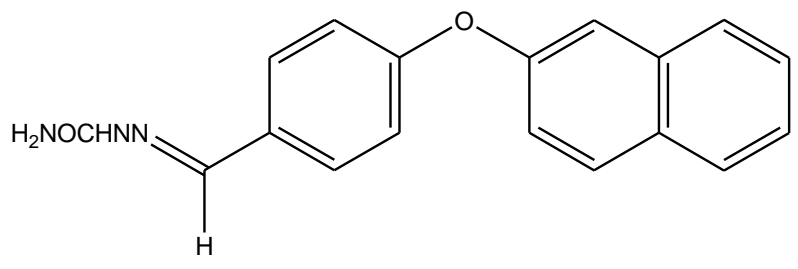

6

More efforts have been done in the semicarbazone research field by Pandeya $\boldsymbol{e t}$ al. (1999). They have adopted a new concept by attaching another lipophilic moiety at the terminal primary amino function. This modification realized that the terminal primary amino $\left(\mathrm{NH}_{2}\right)$ group is not essential for anticonvulsant activity and substituting one proton will enhance or at least retain the activity. Investigations in this aspect were started in 1999 through synthesizing a series of 2-nitrobenzaldehyde semicarbazones. The anticonvulsant activity was screened against MES, scPTZ tests in addition to scSTY seizures test which throws light for the interaction with glycine receptors. Compound 7 was the most active in all tests $(100 \mathrm{mg} / \mathrm{kg}$ MES, $300 \mathrm{mg} / \mathrm{kg} \mathrm{scPTZ}$ and $30 \mathrm{mg} / \mathrm{kg}$ scSTY).

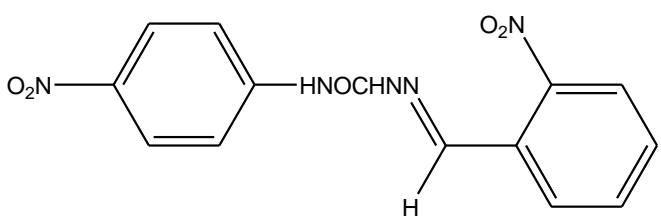

7

In the same vein, Pandeya et al. (2001) studied the effect of using different substituted benzaldehydes at the distal hydrophobic domain and different substituted phenyl moieties at the primary amino functionality of semicarbazones. Many compounds provided significant protection against MES and scSTY where compound $\mathbf{8}$ displayed the best activity at a dose of $30 \mathrm{mg} / \mathrm{kg}$ in scSTY test.

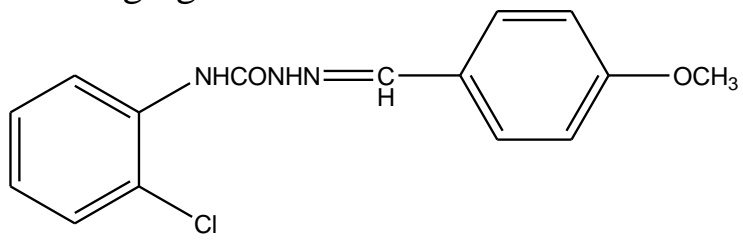

8

Another study has been performed by Pandeya et al. (2000) utilizing the reported importance of 4-bromophenyl moiety in biologically active compounds as anticonvulsants (Unverferth $\boldsymbol{e t}$ al., 1998). They prepared a series of 4-bromophenyl semicarbazones of aliphatic aldehydes. The semicarbazone derivatives were examined in MES, scPTZ and scSTY screens. Semicarbazone 9 showed the greatest activity, being active in all screens (300 mg/kg for MES and scSTY, $100 \mathrm{mg} / \mathrm{kg}$ for scPTZ) with very low neurotoxicity and no sedative-hypnotic activity.

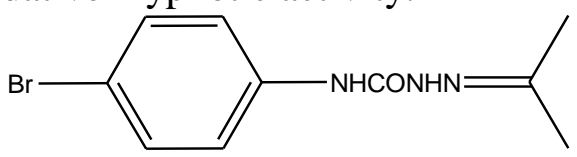

9

For activity enhancement, Pandeya et al. (2002) have combined the 4bromophenyl moiety with the versatile heterocyclic hydrophobic isatin molecule which has preliminary anticonvulsant activity (Sareen et al., 1962). Thus, a series of substituted 
isatin semicarbazones has been prepared. Compound $\mathbf{1 0}$ has emerged as the most active analog showing good activity in all the three tests $(100 \mathrm{mg} / \mathrm{kg}$ MES, $30 \mathrm{mg} / \mathrm{kg} \mathrm{scPTZ}$, and $300 \mathrm{mg} / \mathrm{kg} \mathrm{scSTY}$ ) and was more active than phenytoin and valproic acid.

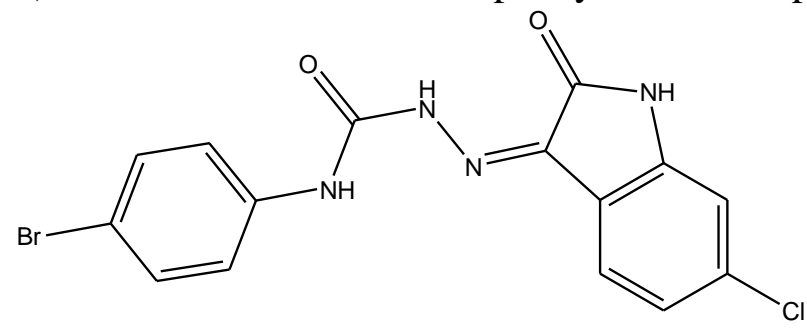

10

Additional structural modifications of isatin containing semicarbazones have been achieved by Smitha $\boldsymbol{e t}$ al. (2008). They have prepared a series of $N$-methyl/acetyl 5-(un)substituted isatin-3-semicarbazones which were subjected to several pharmacological screens (MES, scPTZ, and scSTY). Among the prepared compounds, compound 11 showed broad-spectrum anticonvulsant activity as indicated by its protection in scSTY (300 mg/kg), MES and scPTZ (100 mg/kg) screens.

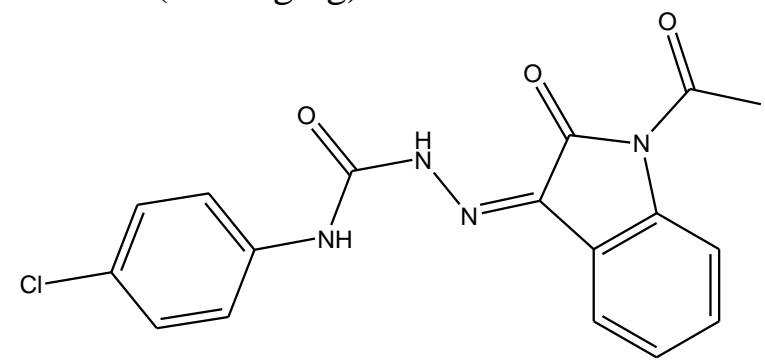

11

Pandeya et al. (2003) performed another study in order to confirm the essentiality of the hydrogen bonding domain (HBD) and the influence of its isosteric modifications. Therefore, the $-\mathrm{NHCO}-$ pharmacophore has been replaced by $-\mathrm{OCH}_{2}-$ group. Compounds with - NHCO- were found to be the most active in MES, scPTZ and scSTY tests. These compounds were also active in the MES test after oral administration in rats. Compound 12 was found to be the most active in all tests $(300 \mathrm{mg} / \mathrm{kg}$ in MES, $100 \mathrm{mg} / \mathrm{kg}$ in scPTZ and scSTY). On the other hand, compounds with $-\mathrm{OCH}_{2}-$ isostere were devoid of anticonvulsant activity. This study revealed that the hydrogen bonding domain in semicarbazones, adjacent to the lipophilic aryl ring, is essential for the anticonvulsant activity.

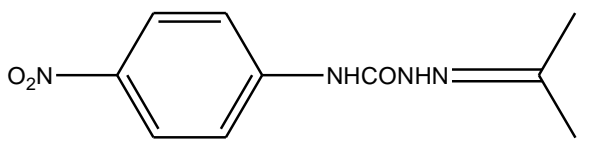

12

Later on Pandeya et al. (2003) have synthesized a series of semicarbazones aiming at testing the effect of increasing the lipophilicity on the anticonvulsant activity. The study has shown that introduction of ethyl at the terminal amino group led to increased activity and decreased toxicity. Compound $\mathbf{1 3}$ dispayed 100\% protection at 300 $\mathrm{mg} / \mathrm{kg}$ in MES and scPTZ screens. 


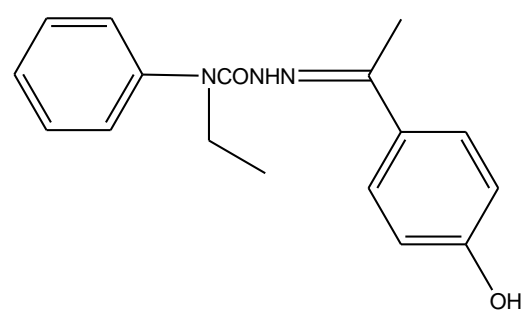

13

In another approach to increase the lipophilicity [50], Pandeya et al. have prepared several semicarbazones of $p$-chloroacetophenone Mannich bases where compound $\mathbf{1 4}$ was the most active candidate. In a related study in 2007 (Raja et al., 2007), have synthesized new series of acetophenone and $p$-chloroacetophenone Mannich bases semicarbazones. It is established that compound $\mathbf{1 5}$ has excellent anticonvulsant activity in MES $(300 \mathrm{mg} / \mathrm{kg}$ i.p in mice and $30 \mathrm{mg} / \mathrm{kg}$ oral in rat) and scPTZ $(300 \mathrm{mg} / \mathrm{kg})$ tests. The inclusion of an additional moiety $\left(\mathrm{CH}_{2}-\mathrm{CH}_{2}-\mathrm{N}<\right)$ retained the anticonvulsant activity.

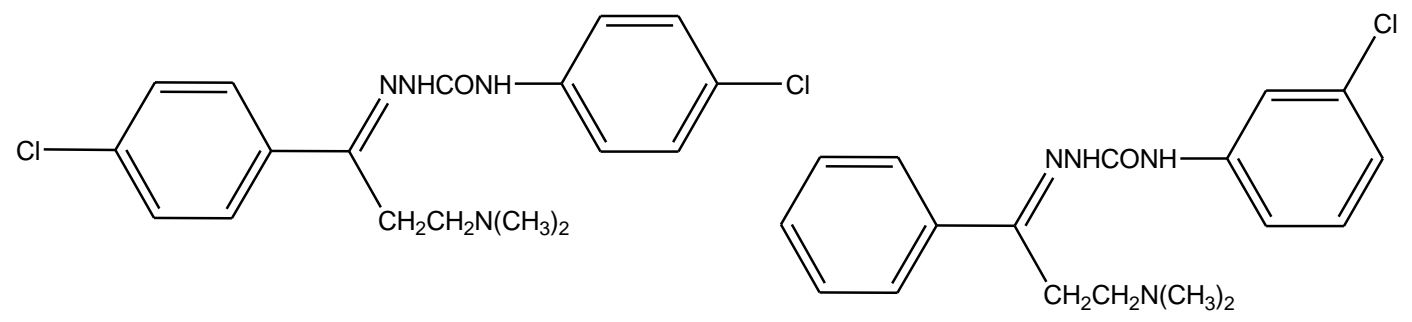

14

15

As a continuation of the aforementioned investigations, Yogeeswari and his group started a new intensive work aiming at better understanding of the pharmacophoric binding site and particularly oriented towards the effect of aryl ring substitutions on the activity of semicarbazones as anticonvulsants. Thus, based on the reports stating that substitutions in the proximal aryl ring by halogens, particularly bromide, have been found to increase potency in the MES screen (Pandeya et al., 2000; Pandeya et al., 2001; Pandeya et al., 2002). Yogeeswari et al. (2003) have prepared a series of 3-bromophenyl semicarbazone derivatives. Compound 16 showed anticonvulsant activity in MES and scPTZ tests with $\mathrm{ED}_{50}=32.35 \mathrm{mg} / \mathrm{kg}$ and $<45 \mathrm{mg} / \mathrm{kg}$ respectively.

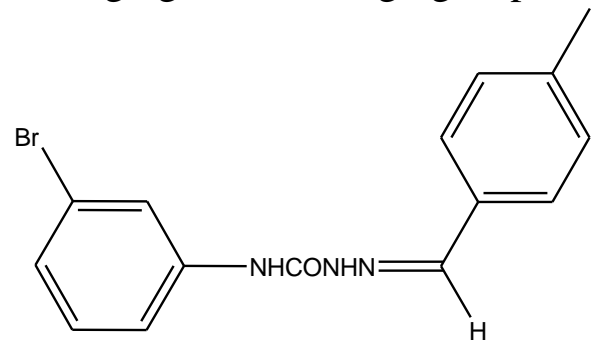

16

Motivated by the activity of 3-halo phenyl semicarbazone derivatives (compound 16) and the reported benefit of 2-methyl substituted phenyl ring on the anticonvulsant activity (Pavia et al., 1990; Bailleux et al., 1994; Moreau et al., 1994), Yogeeswari et 
al. (2004) have synthesized a series of 3-chloro-2-methylphenyl substituted semicarbazones. The semicarbazone derivatives were examined in MES, scPTZ and scSTY screens. Compound $\mathbf{1 7}$ showed the best results by exhibiting anticonvulsant potency against all the three screens $(300 \mathrm{mg} / \mathrm{kg}$ for MES and scPTZ, $100 \mathrm{mg} / \mathrm{kg}$ for scSTY) with lesser neurotoxicity.

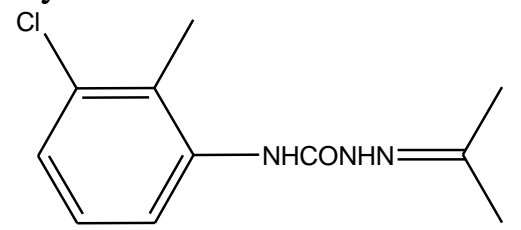

17

The endowed anticonvulsant properties of semicarbazones substituted in the proximal aryl ring by electron withdrawing atom/group and the anticonvulsant activity of sulphonamide derivatives, (Sulthiame (18) Ospolot ${ }^{\circledR}$ ) (Tanimukai et al., 1965), (Zonisamide (19) Zonegran ${ }^{\circledR}$ ) (Masuda et al., 1980) and other compounds (Hamor and Reavlin 1967; Oles et al., 1989), act as an impetus for Yogeeswari et al. (2004) to prepare a series of 4-sulphamoylphenyl semicarbazone derivatives.

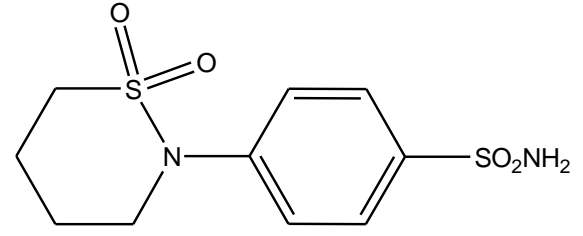

18

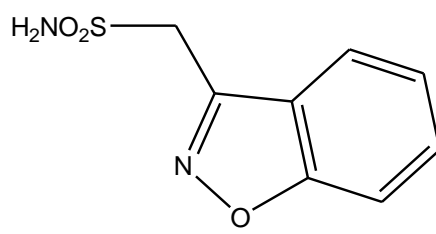

19

Among the new evaluated derivatives, 4-methyl acetophenone derivative $\mathbf{2 0}$ emerged as the most active compound as indicated by its protection in MES $(100 \mathrm{mg} / \mathrm{kg})$ and scSTY $(300 \mathrm{mg} / \mathrm{kg})$ screens with low neurotoxicity.

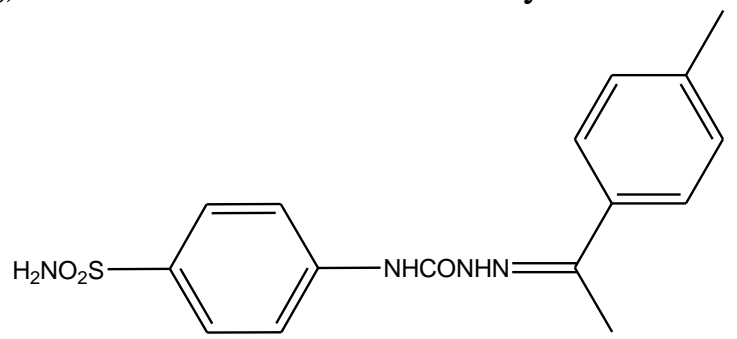

20

In a further study, Yogeeswari et al. 2005 have prepared a series of 4ethoxyphenyl semicarbazones aiming to evaluate their biological activity and estimate the spatial compatibility of the arylsemicarbazones with the general pharmacophore model of the anticonvulsant activity (two aromatic rings or their equivalent in a favored orientation and a third region containing a number of hydrogen bonding forming functional groups). Most of the tested compounds showed protection from seizures in MES and scPTZ screens. Compound 21 was the most active derivative responding in both models at 100 $\mathrm{mg} / \mathrm{kg}$. The study revealed that arylsemicarbazones fulfill the essential demands of previously mentioned pharmacophoric model of anticonvulsant and suggested that the anticonvulsant activity was exerted through GABA-mediated mechanism. 


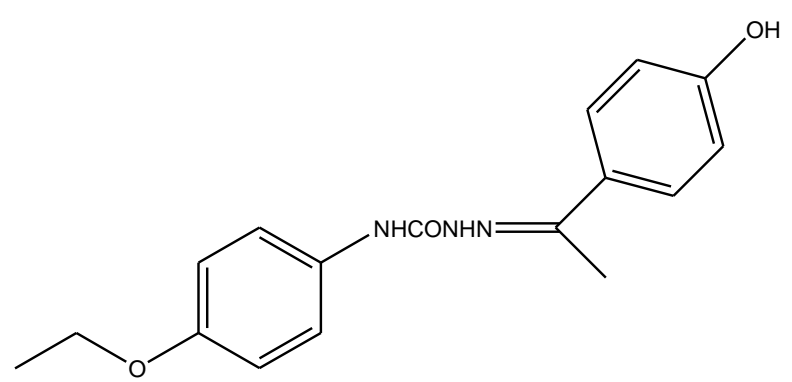

21

The successful $N^{4}$-(substituted phenyl) semicarbazones profile as anticonvulsant along with the reported potent activity against MES seizures of some 2,6-dimethylphenyl derivatives (Clark et al., 1986; Vamecq et al., 2000) advocated Yogeeswari $\boldsymbol{e t}$ al. (2005) to prepare a series of 2,6-dimethylphenyl semicarbazones to find a superior compound that would exhibit a broad spectrum of anticonvulsant activity with less or no toxicity. The 2-hydroxybenzaldehyde derivative $\mathbf{2 2}$ emerged as a prototype wide spectrum anticonvulsant agent active in five models (MES $100 \mathrm{mg} / \mathrm{kg}, \mathrm{scPTZ} 300 \mathrm{mg} / \mathrm{kg}$, scSTY $30 \mathrm{mg} / \mathrm{kg}$, scPIC $30 \mathrm{mg} / \mathrm{kg}$ and the kindling model of seizure $100 \mathrm{mg} / \mathrm{kg}$ ) with no neurotoxicity and hepatotoxicity. As well, it increased the 4-aminobutyric acid (GABA) level by $118 \%$ and inhibited the GABA transaminase enzyme.

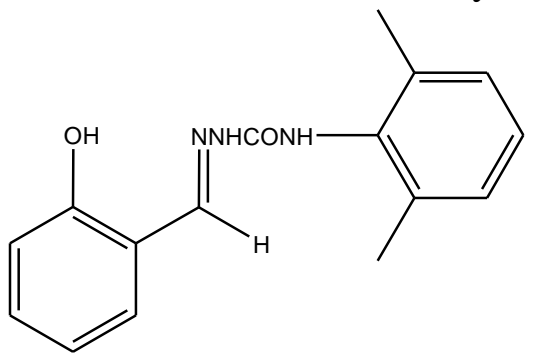

22

In a different study by Yogeeswari et al. (2006) and as further improvement of 22 anticonvulsant activity, compound $\mathbf{2 3}$ exhibited a potent anticonvulsant activity in both MES and scPTZ screens in a series of 2-hydroxybenzaldehyde semicarbazones.

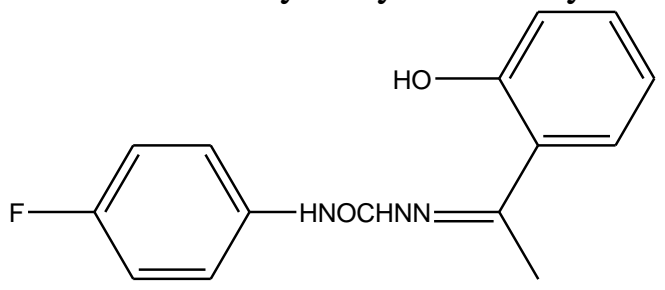

23

Further investigations of the $N^{4}$-(substituted phenyl) semicarbazones activity have been performed by Yogeeswari et al. (2006) through preparation of several 2,4dimethylphenyl substituted semicarbazones. The synthesized semicarbazones were effective in MES, scPTZ and scSTY models and additional evidents were found realizing the GABA-mediated mechanism. Compound $\mathbf{2 4}$ revealed as the most potent derivative in this series with activity against all tested models $(100 \mathrm{mg} / \mathrm{kg}$ for MES and scPTZ and 300 $\mathrm{mg}$ for $\mathrm{scSTY}$ ). 


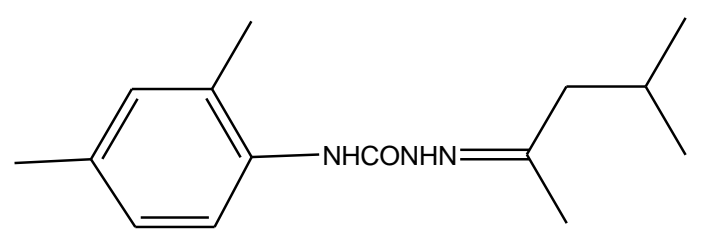

24

In a closely related study within Yogeeswari group in 2006 (Thirumurugan $\boldsymbol{e t}$ al., 2006), have prepared a series of 2,4-dimethoxyphenyl semicarbazones. Among which the propan-2-one derivative 25 was the most active compound (100 $\mathrm{mg} / \mathrm{kg}$ for MES and $\mathrm{scSTY}$ and $300 \mathrm{mg}$ for scPTZ) with no neurotoxicity. In addition, it elevated GABA levels in the midbrain and medulla oblongata regions equipotent to clobazam.

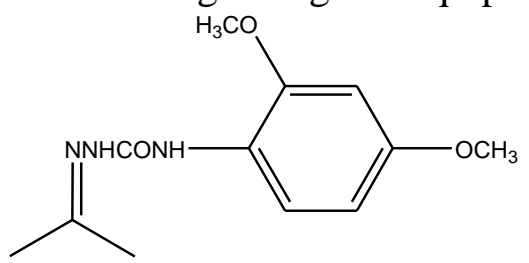

25

In a hybrid pharmacophoric approach towards CNS depressant candidates, Yogeeswari et al. (2007) have synthesized a series of newer $y$-aminobutyric acid (GABA) aryl semicarbazones. The synthesized derivatives of the inhibitory neurotransmitter GABA exert CNS depressant activity (including anticonvulsant activity) through expected enhancement of peripheral GABAergic neurotransmission. Compound 26 revealed as potent anticonvulsant showing protection against MES, scPIC, and scSTY at $300 \mathrm{mg} / \mathrm{kg}$ and lower neurotoxicity.

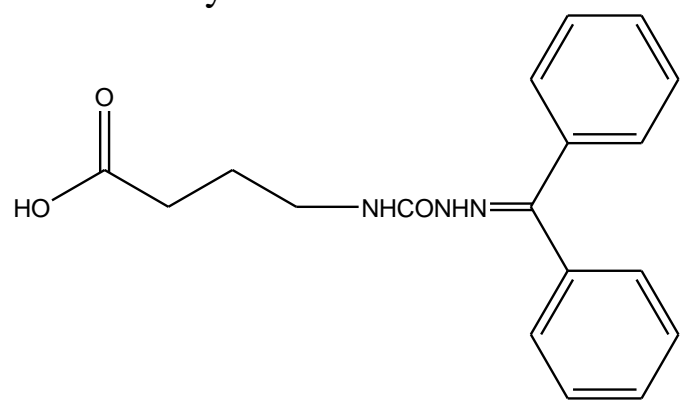

26

Further series of contributions have been introduced by Aggarwal $\boldsymbol{e t}$ al. to explore the size and the functional requirements of the distal hydrophilic-hydrophobic site of semicarbazones to exert their anticonvulsant activity. Thus, two terpenes namely, citral and $R$-(-)carvone, have been used for synthesis of a series of 4-substituted aryl semicarbazones by Aggarwal and Mishra (2004). All synthesized compounds exhibited significant protection after i.p. administration in MES test while $72 \%$ exhibited protection in scPTZ test. The results showed that terpenes fulfill the structural requirements for anticonvulsant activity in MES as well as scPTZ test. The 4-F-phenyl semicarbazone 27 emerged as the most active analog (100 mg/kg MES and $300 \mathrm{mg} / \mathrm{kg}$ scPTZ). 


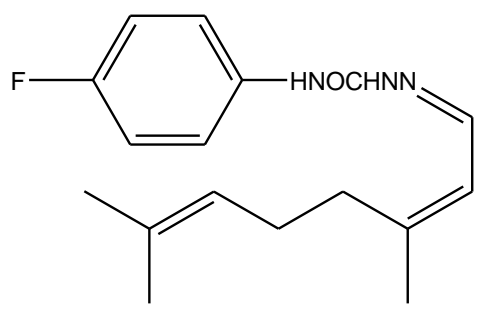

27

Utilizing the fact that many anticonvulsants have carboxylate group in their structure and as further investigation of the distal hydrophilic-hydrophobic site, Aggarwal and Mishra (2005) have synthesized a series of 4-substituted aryl semicarbazones of levulinic acid (4-oxo-pentanoic acid). 4-Flurophenyl semicarbazone of levulinic acid $\mathbf{2 8}$ emerged as the most active congener showing a broad spectrum of anticonvulsant activity (MES $100 \mathrm{mg} / \mathrm{kg}$, scPTZ $300 \mathrm{mg} / \mathrm{kg}$ ) with low neurotoxicity. Whereas, $N^{4}$ - unsubstituted levulinic acid semicarbazone was found to be inactive in all screens.

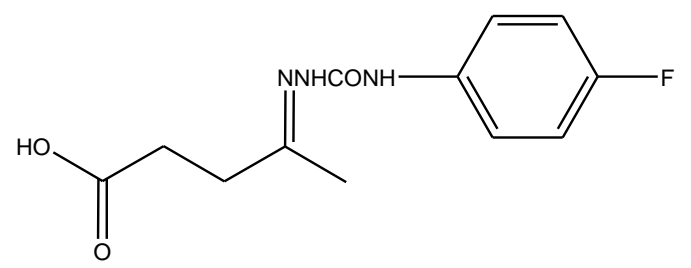

28

In a further investigations on $N^{4}$ - unsubstituted semicarbazones, Aggarwal et al. have prepared the unsubstituted semicarbazones of citral, carvone and levulinic acid (Aggarwal et al., 2008). Results revealed that the anticonvulsant activity will be retained when lipophilic distal aryl ring replaced with non-cyclic lipophillic groups (carvone (29) $300 \mathrm{mg} / \mathrm{kg}$ for both models and citral (30)100 mg/kg for MES and $300 \mathrm{mg} / \mathrm{kg}$ for scPTZ) but not with hydrophilic substituents (levulinic acid). It could be explained through the blood brain barrier (BBB) invasion inability of lipophobic molecules.

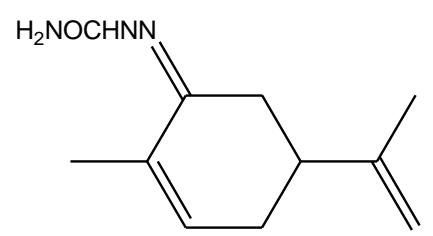

29

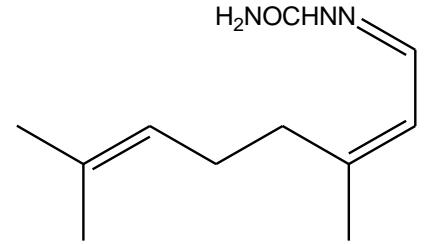

30

In another study on terpenes by Verma et al. (2009), a series of menthone semicarbazones has been prepared. The anticonvulsant potential of the compounds was investigated using MES and scPTZ models. Based on the pharmacological investigations compound $\mathbf{3 1}$ has evolved to be the most active compound among the series showing protection against both models at $100 \mathrm{mg} / \mathrm{kg}$.

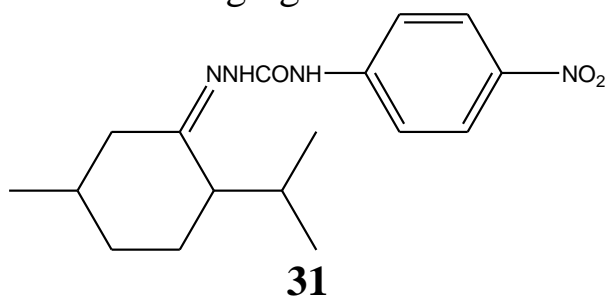


As an isostere of phenyl ring, pyridyl carbaldehydes and methyl ketones have been indulged in a semicarbazone structures by Aggarwal et al. (2009) to afford a series of 4-aryl substituted pyridine semicarbazones. In this study compound $\mathbf{3 2}$ emerged as the most active derivative showing activity at $100 \mathrm{mg} / \mathrm{kg}$ in MES and scPTZ tests with prolonged duration of action. In the light of above results the semicarbazones of pyridyl containing carbonyl compounds emerge as lead molecules, showing broad spectrum of activity with low neurotoxicity and prolong duration of action on oral administration.

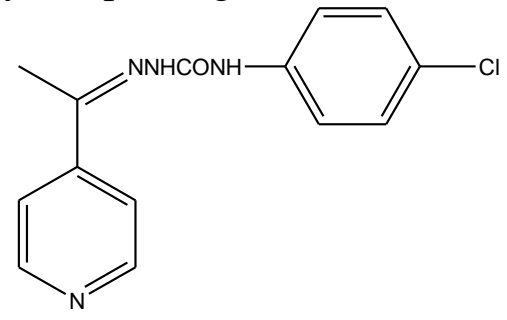

32

In a related study, Mehta et al. have synthesized a series of substituted (3methylpyridin-2-yl) semicarbazones (Mehta et al., 2006). The synthesized compounds were evaluated for their anticonvulsant activity by MES, scPTZ, scSTY, and scPIC. The isatin semicarbazone 33 was the most active analog of the series (100 mg/kg in MES and scSTY, and $300 \mathrm{mg} / \mathrm{kg} \mathrm{scPIC)}$, being more efficacious in most of the tested models than ethosuximide and sodium valporate.

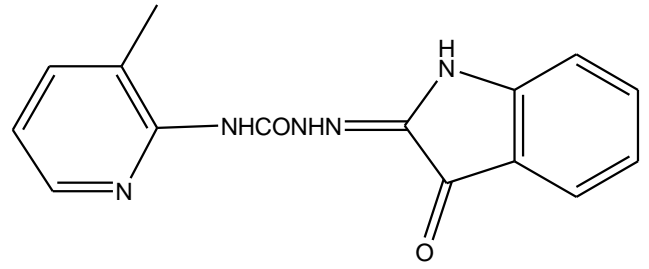

33

More pyridyl semicarbazones have been introduced by Shafiee et al. (2009). They have synthesized a new series of 4-(2-phenoxyphenyl)pyridyl semicarbazones as potential anticonvulsant agents. All the prepared compounds were evaluated for their anticonvulsant activity in PTZ-induced kindling model. The results showed that two compounds (34 and $\mathbf{3 5}$ ) showed greater protection from seizure than sodium valproate at dose of $100 \mathrm{mg} / \mathrm{kg}$.

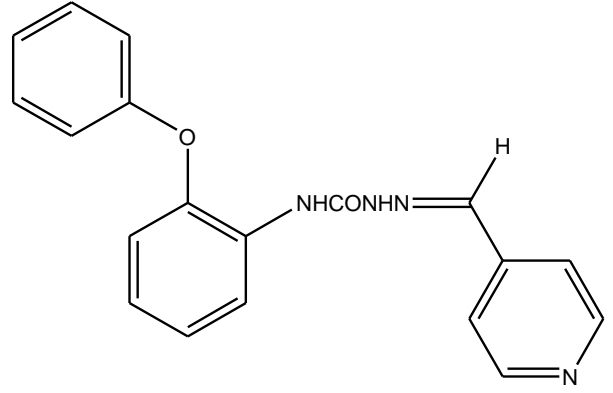

34

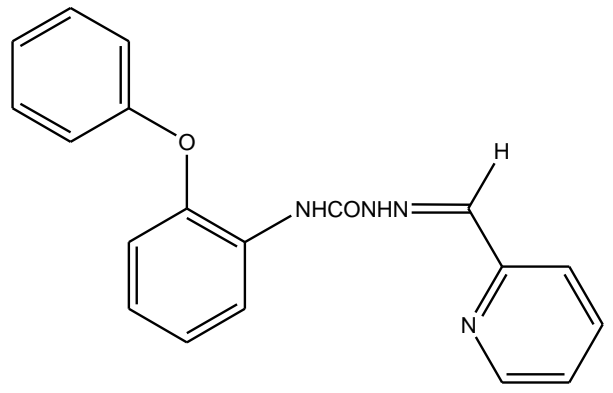

35

In a series of studies aiming to validate the semicarbazone based pharmacophoric model, Rajak et al. (2009) have prepared a series of 2,5-disubstituted 1,3,4-thiadiazole semicarbazones as a hybrid structure of 1,3,4-thiadiazole moiety as anticonvulsant pharmacophore (Dogan et al., 2002; Jatav et al., 2008) and semicarbazone functionality. 
The anticonvulsant potential of the synthesized compounds was investigated using MES and scPTZ models. Compound $\mathbf{3 6}$ was found to possess significant anticonvulsant activity at $100 \mathrm{mg} / \mathrm{kg}$ in both the models.

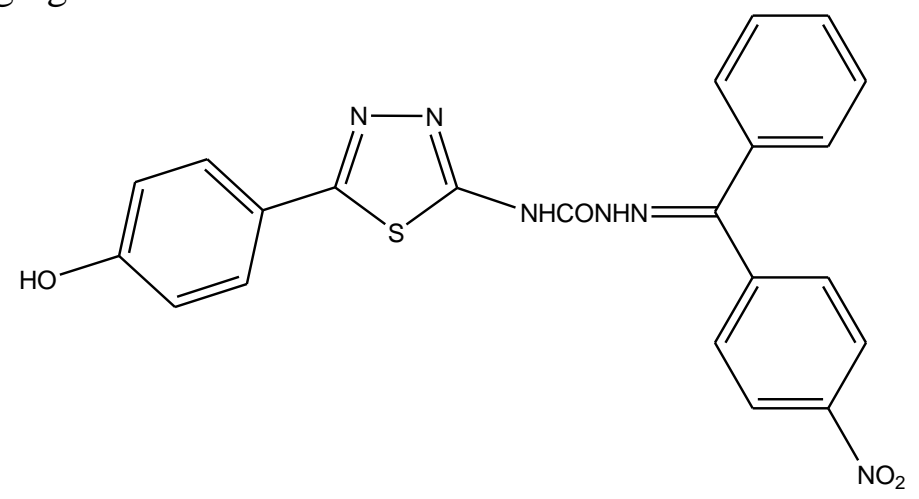

36

Further investigation of 1,3,4-thiadiazole semicarbazones by Rajak et al. (2010) has been performed through substituting indolyl group at position 5. the new compounds have been evaluated for their anticonvulsant potential using MES and scPTZ screens. Compound 37 came out as the most active compound showing activity in both MES (100 $\mathrm{mg} / \mathrm{kg}$ ) and scPTZ (300 mg/kg) without neurotoxicity.

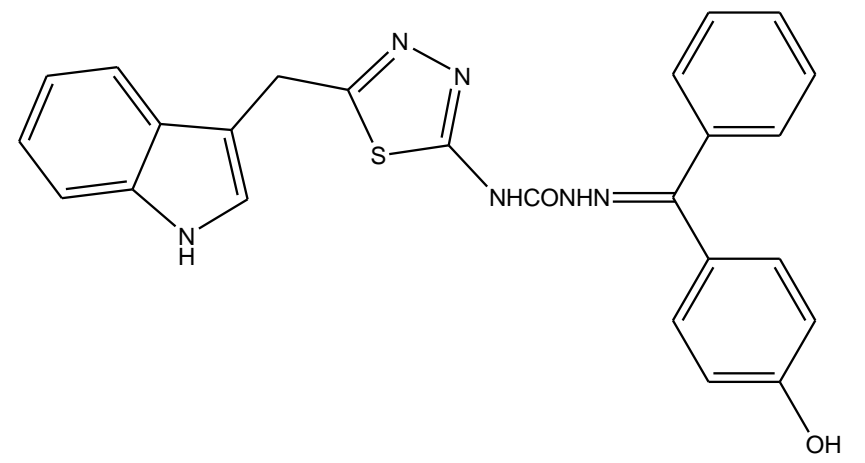

37

The oxygen isostere of 1,3,4-thiadiazole semicarbazones, 1,3,4-oxadiazole, has been prepared by the same group in 2009 and 2010. A series of 2,5-disubstituted-1,3,4oxadiazole semicarbazones has been synthesized and evaluated for its anticonvulsant activity. Compound in the first study $\mathbf{3 8}$ showed considerable activity in MES at 100 $\mathrm{mg} / \mathrm{kg}$ and scPTZ at $300 \mathrm{mg} / \mathrm{kg}$ without any neurotoxicity. While in the second study, compound 39 displayed broad spectrum anticonvulsant activity (100 mg/kg for MES and scPTZ and $300 \mathrm{mg} / \mathrm{kg}$ for scSTY) and absence of neurotoxicity (Rajak 2009; 2010).

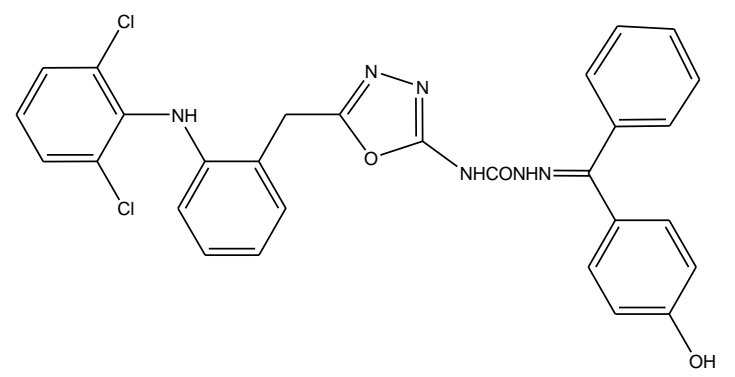




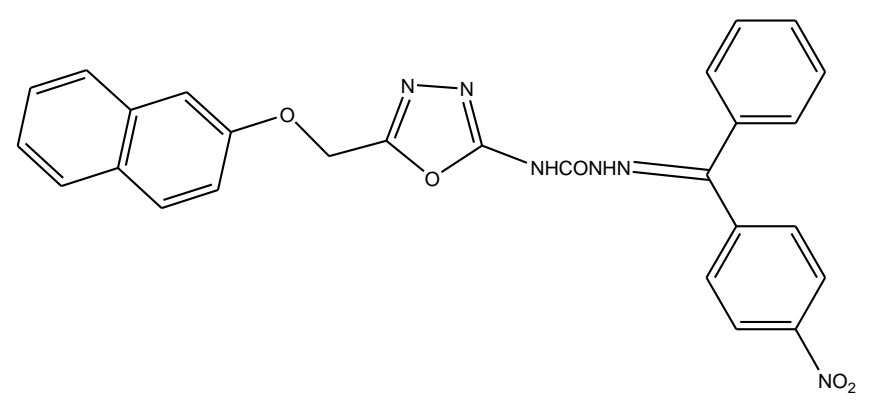

39

New hybrid pharmacophoric approach has been introduced by Siddiqui $\boldsymbol{e t}$ al . (2007) through combining the anticonvulsant benzothiazole moiety with semicarbazone group. A series of 1,3-benzothiazol-2-yl semicarbazones has been synthesized and screened for MES activity. Compounds with 4-Cl and 4-alkyl substituted phenyl ring of benzothiazole moiety showed the best results and substitution with $\mathrm{NO}_{2}$ at the distal aryl ring showed favored MES activity (compound $\mathbf{4 0}$ showed $100 \%$ protection at $30 \mathrm{mg} / \mathrm{kg}$ ).

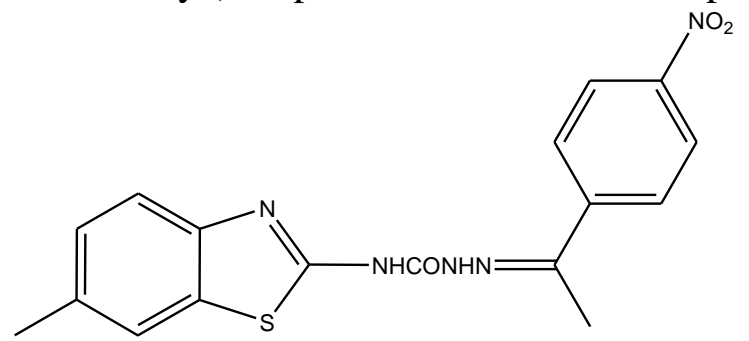

40

In a further work, Siddiqui et al. (2009) have synthesized a series of coumarinthiazole incorporated semicarbazones. The synthesized compounds were tested for anticonvulsant activity utilizing PTZ and MES tests. Compound $\mathbf{4 1}$ exhibited significant anticonvulsant activity in all models (30 mg/kg MES and $100 \mathrm{mg} / \mathrm{kg} \mathrm{scPTZ}$ ) with out toxicity.

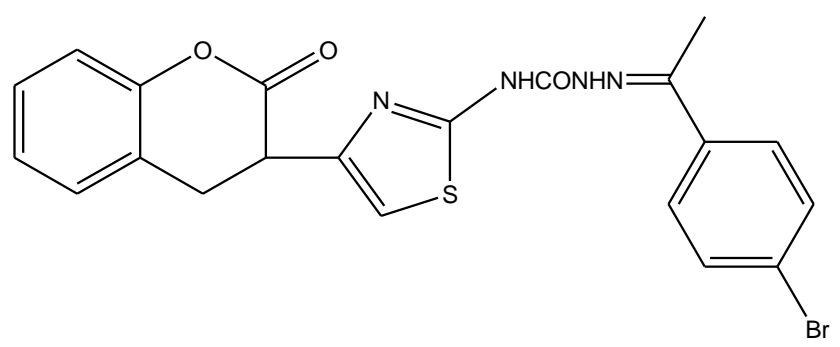

41

Another series of thiazole semicarbazones has been introduced by Azam $\boldsymbol{e t}$ al . (2009). Thus, a series of (naphtha[1,2-d]thiazol-2-yl) semicarbazones has been prepared and examined against MES and PTZ in mice and rats. Compound $\mathbf{4 2}$ was revealed as the most active compound in all performed pharmacological screens at $100 \mathrm{mg} / \mathrm{kg}$. 


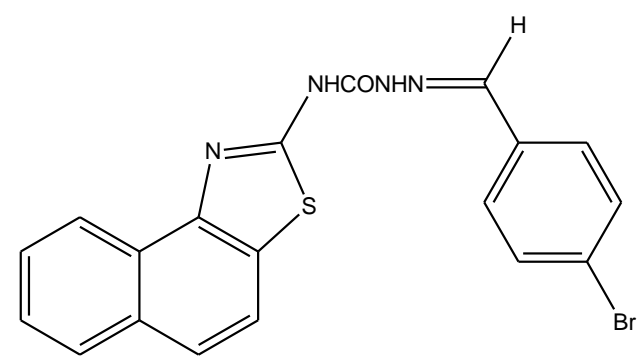

42

Utilizing the anticonvulsant activity of quinazolinone (Georgey et al., 2008; Ilangovan et al., 2010) have synthesized a series of substituted quinazolinone semicarbazones. The newly synthesized compounds were evaluated intraperitoneally into the mice in MES and scSTY screens. Almost all the synthesized analogues were equipotent to phenytoin with very low neurotoxicity profile. Compound $\mathbf{4 3}$ showed the best protection in both models at $30 \mathrm{mg} / \mathrm{kg}$ without neurotoxicity.<smiles>O=C(N=Cc1ccccc1O)Nn1c(-c2ccccc2)nc2ccccc2c1=O</smiles>

43

Another hybrid series of the prominent anticonvulsant pyrimidine moiety (Santagati et al., 1996) and semicarbazone has been introduced by Alam et al. (2010). They have synthesized a number of (4,6-substituteddiphenylpyrimidin-2-yl) semicarbazones. The new compounds have been tested for their anticonvulsant activity against MES and scPTZ. Among these compounds, 44 was found to be remarkably active in both seizure models (30 mg/kg for MES and $100 \mathrm{mg} / \mathrm{kg}$ for scPTZ).

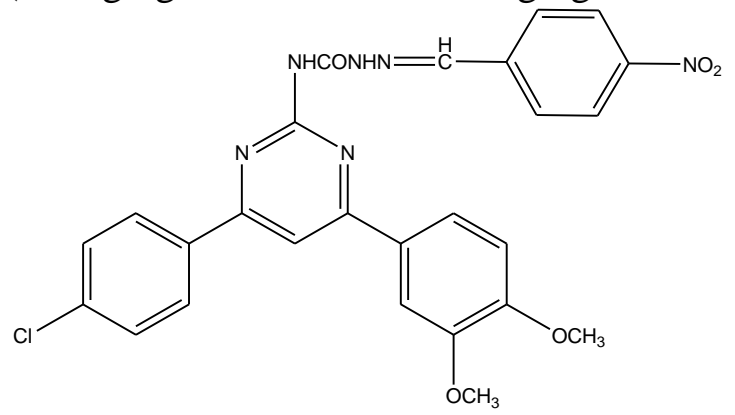

44

Azam et al. (2010) have prepared a series of 1-(substituted benzylidene/ ethylidene)-4-(naphthalen-1-yl) semicarbazones. The anticonvulsant activities were evaluated by both MES and PTZ tests. Compound 45 possessed the highest protection profile at $100 \mathrm{mg} / \mathrm{kg}$ against MES and PTZ tests that was coinciding with the computational study. 


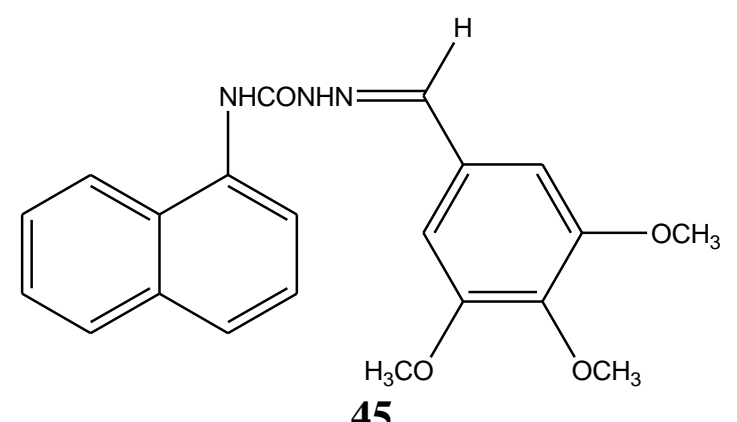

Applications of semicarbazones in radio-induced convulsions have been reported firstly by Taroua et $\boldsymbol{a l}$. (1996). They have utilized the radio-protective activity of dithiolane (Lawa, et al., 1994) to prepare a series of $\alpha, \beta$ and $\gamma$-keto-1,3-dithiolane semicarbazones as protective agents against radio-induced convulsions. Some of the synthesized compounds showed radio-protective effect over $90 \mathrm{~min}$. compound $\mathbf{4 6}$ was the most active with respect to duration and number of survivals (90\% over $90 \mathrm{~min}$ at 400 $\mathrm{mg} / \mathrm{kg}$ ).

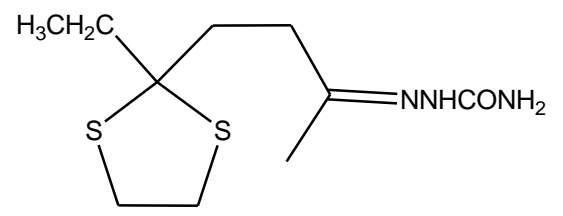

46

In the same vein, contribution has been made by Micale et al. (2005). A series of 2-semicarbazonomethyl-4,5-methylenedioxyphenylacetic acid has been synthesized as anticonvulsant against sound-induced seizures. The newly synthesized compounds showed a comparable activity to the potent anticonvulsant 1-(4-aminophenyl)-4-methyl7,8-methylenedioxy-5H-2,3-benzodiazepine (47 GYKI 52466) (Sólyom and Tarnawa 2002). Compound 48 was the most active derivative ( $\mathrm{PI}=3.6)$.

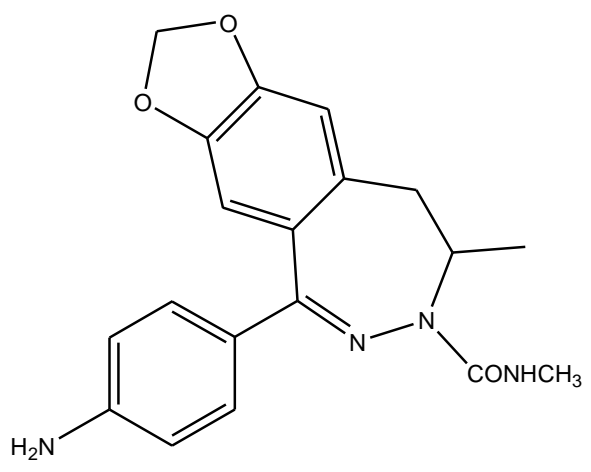

GYKI $52466(47)$<smiles></smiles>

48 


\section{REFERENCES:}

Aggarwal, N., Aggarwal R., Mishra P., Jain J.S., Bansal S.K., Jha K.K. (2008): "Design and Evaluation of Semicarbazones and Thiosemicarbazones as Novel Anticonvulsants." Central Nervous System Agents in Medicinal Chemistry 8: 26-28.

Aggarwal, N., Mishra P., Nagori B. P., Aggarwal R., Jain J. (2009): "Anticonvulsant and neurotoxicity evaluation of some N4 phenyl substituted pyridyl semicarbazones." Central Nervous System Agents in Medicinal Chemistry 9: 295-299.

Aggarwal, N., Mishra, P. (2004): "Synthesis of 4-aryl substituted semicarbazones of some terpenes as novel anticonvulsants." J Pharm Pharmaceut Sci 7: 260-264.

Aggarwal, N., Mishra, P. (2005): "Synthesis and evaluation of 4-substituted semicarbazones of levulinic acid for anticonvulsant activity." $\underline{\mathrm{J} \text { Zhejiang Univ }}$ Sci B 6: 617-621.

Alam, O., Mullick, P., Verma, S.P., Gilani, S. J., Khan, S. A., Siddiqui, N., Ahsan, W. (2010): "Synthesis, anticonvulsant and toxicity screening of newer pyrimidine semicarbazone derivatives." Euro. J. Med. Chem. 45: 2467-2472.

Azam, F., El-gnidi B. A., Alkskas I. A. (2010): "Combating oxidative stress in epilepsy: Design, synthesis, quantum chemical studies and anticonvulsant evaluation of 1-(substituted benzylidene/ethylidene)-4-(naphthalen-1-yl)semicarbazides." Euro. J. Med. Chem. 45: 2817-2826.

Azam, F. l., Alkskas, I. A., Khokra, S. L., Prakash, O. (2009): "Synthesis of some novel $\mathrm{N}^{4}$-(naphtha[1,2-d]thiazol-2-yl)semicarbazides as potential anticonvulsants." Euro. J. Med. Chem. 44: 203-211.

Bailleux, V., Vallée, L., Nuyts, J. P., Vamecq, J. (1994): "Anticonvulsant activity of some 4-amino-N-phenylphthalimides and N-(3-amino-2methylphenyl)phthalimides." Biomed Pharmacother. 48: 95-101.

Clark, C. R., Lin, C.-M., Sanson, R. T. (1986): "Anticonvulsant activity of 2- and 3aminobenzanilides." J. Med. Chem. 29: 1534-1537.

Dimmock, J. R. (1994): "Preparation of aryl semicarbazone anticonvulsants." WO $\underline{9406758}$.

Dimmock, J. R., Baker, G. B., (1994): "Anticonvulsant activities of 4bromobenzaldehyde semicarbazone." Epilepsia 35: 648-655.

Dimmock, J. R., Jonnalagadda,S.S., Huesein,S., Tewari,S., Quail, J. W., Reid, R. S., Delbaere, L. T. J., Prasad, L. (1990): "Evaluation of some thiosemicarbazone of arylidene ketones and analogues for anticonvulsant activities." Eur. J. Med. Chem. 25: 581-588.

Dimmock, J. R., McCoU, J. M., Wonko, S. L., Thnyer, R. S., Hancock,D. S. (1991): "Evaluation of the thiosemicarbazones of some aryl alkyl ketonesand related compoundn for anticonvulaant activities." Eur.J. Med. Chem. 26: 629-634. 
Dimmock, J. R., Puthucode, R. N. (1996): Preparation of phenoxybenzaldehyde semicarbazones as nervous system agents. WO 96/40628: 51.

Dimmock, J. R., Puthucode, R. N., Smith, J. M., Hetherington, M., Quail, J. W., Pugazhenthi, U., Lechler, T., Stables, J. P. (1996): "(Aryloxy)aryl semicarbazones and related compounds: a novel class of anticonvulsant agents possessing high activity in the maximal electroshock screen." J Med Chem 39(20): 3984-3997.

Dimmock, J. R., Sidhu K. K., Thayer R. S., Mack P., Duffy M. J., Reid R. S., Quail J. W., Pugazhenthi U., Ong A., Bikker J. A., Weavers D. F., (1993): "Anticonvulsant activities of some arylsemicarbazones displaying potent oral activity in the maximal electroshock screen in rats accompanied by high protection indices." J Med Chem 36(16): 2243-2252.

Dimmock, J. R., Sidhul, K. K., Tumberl, S. D., Basranl, S. K., Chenl, M., Quail, J. W., Yang, J., Rozas, I., Weaver, D. F. (1995): "Some aryl semicarbazones possessing anticonvulsant activities." Eur J Med Chem 30: 287-301.

Dimmock, J. R., Smith. D. C., Brenner, J. M., Jonnalagadda, S. S., Sardessai, M. S., Wood, J. D., Bigam, G. E. (1986): "Antiepileptic and antileukemic thiosemicarbazones and semicarbazones of 4-aryl-3-buten-2-ones." Euro. J. Med. Chem. 21: 187-192.

Dimmock, J. R., Vashishtha S.C., Stables J.P. (2000): "Anticonvulsant properties of various acetylhydrazones, oxamoylhydrazones and semicarbazones derived from aromatic and unsaturated carbonyl compounds." Eur. J. Med. Chem. 35: 241-248.

Dimmockl, J. R., Pandeyal, S. N., Quaif, J. W., Pugazhenthiz, U., Allens, T. M., Kao, G. Y., Balzarini, J., DeClercq, E. (1995): "Evaluation of the semicarbazones, thiosemicarbazones and bis-carbohydrazones of some aryl alicyclic ketones for anticonvulsant and other biological properties." Eur J Med Chem 30: 303314.

Dogan, H. N., Duran, A., Rollas, S., Sener, G., Uysal, M. K., Gulen, D. (2002): "Synthesis of new 2,5-disubstituted-1,3,4-thiadiazoles and preliminary evaluation of anticonvulsant and antimicrobial activities." Bioorg. Med. Chem. 10: 2893-2898.

Georgey, H., Abdel-Gawad, N., Abbas, S., (2008): "Synthesis and Anticonvulsant Activity of Some Quinazolin-4-(3H)-one Derivatives." Molecules 13: 25572569.

Hamor, G. H., Reavlin, B. L. (1967): "Anticonvulsants 3. Alkyl esters of 4-bromo-2sulfamoylbenzoic acid and 4-chloro-2-sulfamoylbenzoic acid." J. Pharm. Sci. 56: 134-136.

Ilangovan, P., Ganguly, S., Pandi V., Stables J. P. (2010): "Design and Synthesis of Novel Quinazolinone derivatives as Broad Spectrum Anticonvulsants." Der Pharmacia Lettre 2: 13-21. 
Ilangovan, P., ganguly, S., pandi, V. (2010): "Design and Synthesis of Novel Quinazolinone Derivatives as Broad Spectrum Anticonvulsant and Antimicrobial Agent." Journal of Pharmacy Research 3: 703-706.

Jatav, V., Mishra, P., Kashaw, S., Stables, J.P. (2008): "CNS depressant and anticonvulsant activities of some novel 3-[5-substituted 1,3,4-thiadiazole-2yl]-2-styryl quinazoline-4(3H)-ones." Eur. J. Med. Chem. 43: 1945-1954.

Kadaba, P. K. (1984): "Triazolines. XIIL A"l,P,B-Triazolines, a new claea of anticonvulaanta." J. Pharm. Sci. 73: 860-862.

Kadaba, P. K., Lin, Z., Lexington, K., Bethesda, M. (1999): "Hydrazones, hydrazines, semicarbazones and thiosemicarbazones derived from pyridyl ketones as anticonvulsant drugs and excitatory amino acid antagonists." US 5942527.

Lawa, H., Péra, M. H., Taillandiera, G., Fatomeb, M., Lavalb J. D., Leclerca, G. (1994): "New $\gamma$-thiazolidine-1,3-dithiolanes as radioprotectors." Euro. J. Med. Chem. 29: 121-125.

Masuda, Y., Karasawa, T., Shiraishi, Y., Hori, M., Yoshida, K., Shimizu, M. (1980): "3Sulfamoylmethyl-1,2-benzisoxazole, a new type of anticonvulsant drug. Pharmacological profile,." Arzneim.-Forsch. /Drug Res. 30: 477-483.

Mehta, S., Pavana, R. K., Yogeeswari, P., Sriram, D., Stables, J. (2006): "Heteroarylsubstituted semicarbazones: synthesis and anticonvulsant activity of N-(3methylpyridin-2-yl)-substituted semicarbazones." Journal of Heterocyclic Chemistry 43: 1287-1293.

Micale, N., Zappalà, M., Zuccalà, G., Menniti, F. S., Ferreri, G., De Sarro, G., Grasso, S. (2005): "Synthesis of 2-semicarbazonomethyl-4,5methylenedioxyphenylacetic acids as anticonvulsant agents." Il Farmaco 60: 231-235.

Moreau, S., Coudert, P., Rubat, C., Gardette, D., Vallee-Goyet, D., Couquelet, J., Bastide, P., Tronche, P., (1994): "Synthesis and Anticonvulsant Properties of New Benzylpyridazine Derivatives." J. Med. Chem. 37: 2153-2160.

Oles, K. S., Penry, J. K., Cole, D. L. W., Howard, G. (1989): "Use of acetazolamide as an adjunct to carbamazepine in refractory partial seizures." Epilepsia 30: 7478.

Pandeya, N. S., Kohli, S., Siddique, N., Stables, J. P., (2003): "Synthesis and anticonvulsant activities of 4-n-substituted arylsemicarbazones." pol. j. pharmcol 55: 565 - 571.

Pandeya, S. N., Agarwal, A. K. Singh, A., Stables J. P. (2003): "Design and synthesis of semicarbazones and their bio-isosteric analogues as potent anticonvulsants: The role of hydrogen bonding." Acta Pharmaceutica 53: 15-24.

Pandeya, S. N., Manjula, H., Stables J. P. (2001): "Design of semicarbazones and their bio-isosteric analogues as potential anticonvulsants." Pharmazie 56: 121-124. 
Pandeya, S. N., Ponnilavarasan, I. Pandey, A., Lakhan, R., Stables J. P. (1999): "Evaluation of p-nitrophenyl substituted semicarbazones for anticonvulsant properties." Pharmazie 54: 923-925.

Pandeya, S. N., Raja, A.S., Stables, J.P. (2002): "Synthesis of isatin semicarbazones as novel anticonvulsants - role of hydrogen bonding." J Pharm. Pharmaceut. Sci. 5: 266-271.

Pandeya, S. N., Sowmyalakshmi V., Panda S. S., Pandeya A., Stables J. P., (2003): "Anticonvulsant activity of semicarbazone derivatives of Mannich bases." Indian Journal of Chemistry, Section B: Organic Chemistry Including Medicinal Chemistry 42: 2657-2661.

Pandeya, S. N., Yogeeswari, P. Stables, J. P. (2000): "Synthesis and anticonvulsant activity of 4-bromophenyl substituted aryl semicarbazones." Eur. J. Med. Chem. 35: 879-886.

Pandeya, S. N. P., I. Pandey, A. Lakhan, R. Stables, J. P. (1999): "Evaluation of pnitrophenyl substituted semicarbazones for anticonvulsant properties." Pharmazie 54(12): 923-925.

Pavia, M. R., Lobbestael, S. J.,Taylor, C. P., Hershenson, F. M., Miskell, D. L. (1990): "N-Phenyl-N'-pyridinylureas as anticonvulsant agents." J. Med. Chem. 33: 854-861.

Puthucode, R. N., Pugazhenthib U., Quailb J. W., Stables J. P., Dimmock J. R. (1998): "Anticonvulsant activity of various aryl, arylidene and aryloxyaryl semicarbazones." Eur. J. Med. Chem. 33: 595-607.

Raja, A. S., Pandeya, S. N., Panda, S. S. Stables, J. P. (2007): "Synthesis and anticonvulsant evaluation of semicarbazones of acetophenone mannich bases." Pharmaceutical Chemistry Journal 41: 302-307.

Rajak, H., Behera, C. K., Pawar, R. S., Singour, P. K., Kharya, M. D. (2010): "Synthesis and anticonvulsant evaluation of some novel 2,5-disubstituted 1,3,4-thiadiazoles: pharmacophore model studies." Pharmaceutica 67: 503-510.

Rajak, H., Deshmukh, R. Veerasamy, R. Sharma, A. K. Mishra, P. Kharya, M. D. (2010): "Novel semicarbazones based 2,5-disubstituted-1,3,4-oxadiazoles: one more step towards establishing four binding site pharmacophoric model hypothesis for anticonvulsant activity." Bioorg Med Chem Lett 20(14): 41684172.

Rajak, H., Deshmukh, R., Aggarwal, N. Kashaw, S., Kharya, M. D., Mishra, P. (2009): "Synthesis of Novel 2,5-Disubstituted 1,3,4-Thiadiazoles for Their Potential Anticonvulsant Activity: Pharmacophoric Model Studies." Arch. Pharm. Chem. Life Sci. 342: 453 - 461.

Rajak, H., Veerasamy R., Singour P., Kharya M. D., Mishra P., (2009): "Anticonvulsant activity of a novel series of 2,5-disubstituted 1,3,4oxadiazoles: semicarbazones based pharmacophoric model studies." Letters in Drug Design \& Discovery 6: 456-463. 
Rajak, H. D., R. Aggarwal, N. Kashaw, S. Kharya, M. D. Mishra, P. (2009): "Synthesis of novel 2,5-disubstituted 1,3,4-thiadiazoles for their potential anticonvulsant activity: pharmacophoric model studies." Arch Pharm (Weinheim) 342(8): 453-461.

Santagati, M., Modica, M., Santagati, A., Russo, F., Spampinato, S., (1996): "Synthesis of Aminothienopyrimidine and Thienotriazolopyrimidine Derivatives as Potential Anticonvulsant Agents." Pharmazie 51: 7-11.

Sareen, K., kohli, R. P., Amma, M. K., Gujral, M. L. (1962): "Anticonvulsant drugs based on the neurochemistry of seizures." Indian J Physiol Pharmacol 6: 8794.

Schann, S., Mayer, S. (2008): Preparation of naphthalenedione semicarbazones with antiglutamatergic properties for treating neurological disorders and other diseases. WO 2008/098751 A1: 65.

Shafiee, A., Rineh, A., Kebriaeezadeh, A., Foroumadi, A., Sheibani, V., Afarinesh, M. R. (2009): "Synthesis and anticonvulsant activity of 4-(2phenoxyphenyl)semicarbazones." Med Chem Res 18: 758-769.

Siddiqui, N., Arshad, M. F., Khan, A. S. (2009): "Synthesis of some new coumarin incorporated thiazolyl semicarbazone derivatives as anticonvulsants." Acta Poloniae Pharmaceutica 66: 161-167.

Siddiqui, N., Rana, A., Khan, S. A., Bhat M. A., Haque, S. E. (2007): "Synthesis of benzothiazole semicarbazones as novel anticonvulsants-The role of hydrophobic domain." Bioorg. Med. Chem. Lett. 17: 4178-4182.

Smitha, S., Pandeya S. N., Stables J. P., Ganapathy S. (2008): "Anticonvulsant and Sedative-Hypnotic Activities of N-Acetyl / Methyl Isatin Derivatives." Sci Pharm. 76: 621-636.

Sólyom, S., Tarnawa, I. (2002): "Non-competitive AMPA antagonists of 2,3benzodiazepine type." Curr. Pharm. Des. 8: 913-939.

Tanimukai, H., Inui, M., Hariguchi, S., Kaneko, Z. (1965): "Antiepileptic property of inhibitors of carbonic anhydrase,." Biochem. Pharmacol. 14: 961-970.

Taroua, M., Ribuot, C., Péra, M. H., Taillandier, G., Fatome, M., Laval, J. D., Demenge, P., Leclerc, G. (1996): "New $\alpha, \beta$ and y semicarbazone and thiosemicarbazone 1,3-dithiolanes as radioprotectors. Anticonvulsant activity " Eur. J. Med. Chem 31: 589-595.

Thirumurugan, R., Sriram D., Saxena A., Stablesb J., Yogeeswari P., (2006): "2,4Dimethoxyphenylsemicarbazones with anticonvulsant activity against three animal models of seizures: Synthesis and pharmacological evaluation." Bioorg. Med. Chem. 14: 3106-3112.

Unverferth, K., Engel, J., Hofgen, N., Rostock, A., Gunther, R., Lankau, H.J., Menzer, M., Rolfs, A., Liebscher, J., Muller, B., Hofmann, H.J., (1998): "Synthesis, anticonvulsant activity, and structure-activity relationships of sodium channel blocking 3-aminopyrroles." J. Med. Chem 41: 63-73. 
Vamecq, J., Bac, P., Herrenknecht, C., Maurois, P., Delcourt, P., Stables, J. P. (2000): "Synthesis and anticonvulsant and neurotoxic properties of substituted Nphenyl derivatives of the phthalimide pharmacophore." J. Med. Chem. 43: 1311-1319.

Verma, K., Pandeya, S. N. Singh, U. K. Gupta, S. Prashant Anurag, P. Bhardwaj, G. (2009): "Synthesis and Pharmacological Activity of Some Substituted Menthone Semicarbazone and Thiosemicarbazone Derivatives." International Journal of Pharmaceutical Sciences and Nanotechnology 1: 357-362.

Wang, Y., Cai S. X., Lan N. C., Keana J. F. W., Ilyin V. I., Weber E. (1998): "Carbocyclic and heterocyclic substituted semicarbazones and thiosemicarbazones and their use as sodium channel blockers." WO 9847869.

Yogeeswari, P., Ragavendran, J. V. Sriram, D. Nageswari, Y. Kavya, R. Sreevatsan, N. Vanitha, K. Stables, J. (2007): "Discovery of 4-aminobutyric acid derivatives possessing anticonvulsant and antinociceptive activities: a hybrid pharmacophore approach." J Med Chem 50(10): 2459-2467.

Yogeeswari, P., Ragavendran, J. V., Thirumurugan, R., Induja, S., Sriram, D., Stables, J. P. (2006): "Synthesis and structure-activity relationship on anticonvulsant aryl semicarbazones." Medicinal Chemistry 2: 55-62.

Yogeeswari, P., Sriram, D., Veena, V. Kavya, R. Rakhra, K. Ragavendran, J.V. Mehta, S., Thirumurugan, R., Stables, J. P. (2005): "Synthesis of aryl semicarbazones as potential anticonvulsant agents." Biomedicine \& Pharmacotherapy 59: 51-55.

Yogeeswari, P., Sriram D., Pandeya S. N., Stables J. P., (2004): "4-Sulphamoylphenyl semicarbazones with anticonvulsant activity." IL FARMACO 59: 609-613.

Yogeeswari, P., Sriram, D. Thirumurugan, R. Raghavendran, J. V. Sudhan, K. Pavana, R. K. Stables, J. (2005): "Discovery of N-(2,6-dimethylphenyl)substituted semicarbazones as anticonvulsants: hybrid pharmacophore-based design." J Med Chem 48(20): 6202-6211.

Yogeeswari, P., Sriram, D., Brahmandam, A., Sridharan, I., Thirumurugan, R., Stables, J. P. (2003): "Synthesis of novel aryl semicarbazones as anticonvulsants with GABA-mediated mechanism." Medicinal Chemistry Research 12: 57-68.

Yogeeswari, P., Sriram, D., Thirumurugan, R. Jeewanlal, L. R., Jit, S., Ragavendran, J. V., Kavya, R. Rakhra, K., Saraswat, V. (2006): "Synthesis of $\mathrm{N}^{4}-(2,4-$ dimethylphenyl) semicarbazones as 4-aminobutyrate aminotransferase inhibitors." Acta Pharmaceutica 56: 259-272.

Yogeeswari, P., Thirumurugan R., Kavya R., Samuel J. S., Stables J., Sriram D., (2004): "3-Chloro-2-methylphenyl-substituted semicarbazones: synthesis and anticonvulsant activity." Eur. J Med. Chem. 39: 729-734. 


\section{السيميكاربازونات كمركبات ذات تأثير مضاد للصرع}

للسادة الدكاترة

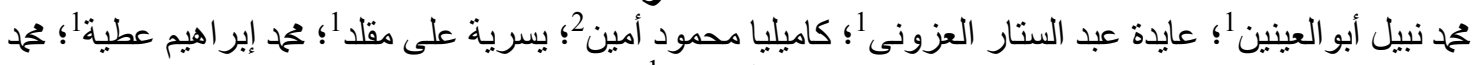

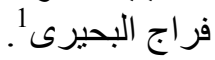

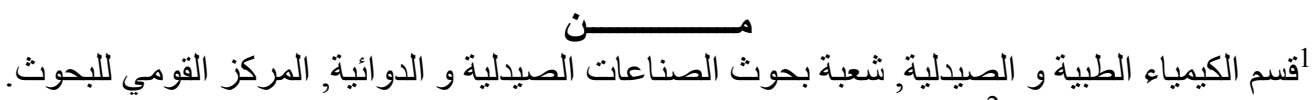

$$
\begin{aligned}
& \text { 2قسم الكيمياء الصيدلية, كلية الصيدلة, جامعة القاهرة. }
\end{aligned}
$$

يعتبر الصرع من أكثر الأمر اض المزمنة انتشار ا حيث يعانى منه أكثر من 1\% من البشر بالإضافة إلى انه

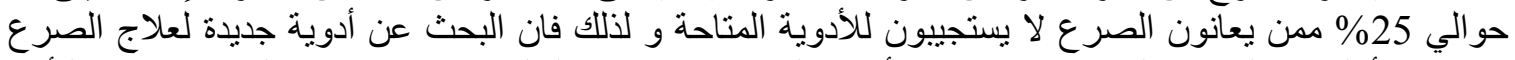

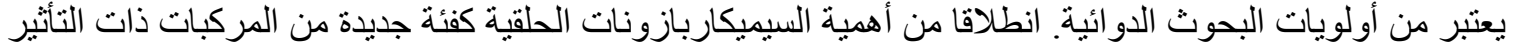

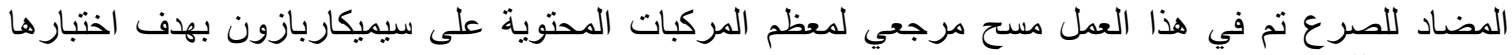

